\title{
Environment of Air-Ions in Healing Chambers in the "Wieliczka" Salt Mine
}

\author{
A. WISZNIEWSKI* \\ Faculty Department of Medical Informatics and Biostatistics, Medical University of Gdańsk, \\ Dębinki 1, 80-211 Gdańsk, Poland
}

(Received October 7, 2014; revised version January 15, 2015; in final form February 20, 2015)

\begin{abstract}
The present paper is an attempt to determine the parameters of air-ions in salt mines. The investigations were aimed at determination of the degree of ionization of air in places where cosmic ray particles do not arrive at. Specifically, measurements were performed in healing chambers in salt mines where establishment of standards in the healing process should be considered as the necessity. Preliminary investigations were carried out in three salt mines using the Gerdien ion counter, with sensitivity approximately of 20 ions $/ \mathrm{cm}^{3}$. The studies have shown that concentrations of small air-ion are in the range of $1200-4700$ ions $/ \mathrm{cm}^{3}$ and remain persistently in adits and medicinal chambers of this mine. It means that the air in the "Wieliczka" Salt Mine is several times more saturated with air-ions as compared to the neutral atmosphere background. According to the existing standards, this ionization level is not only deemed acceptable but also optimal for humans. Because results of unsystematic measurements of ion concentrations performed in different Polish salt mines are quite similar, it is assumed that the results presented in this paper are of universal character, and that comparable ionization level in the all mines would be expected. Due to this fact, it was decided that only one of them "Wieliczka" Salt Mine (Poland) can be selected for further detailed research.
\end{abstract}

DOI: 10.12693/APhysPolA.127.1661

PACS: 79.90.+B, 82.30.Fi, 61.80.Jh

\section{Introduction}

The measurements of air-ion concentration were performed in open air [1-3], forests [2], at sea [3, 4], in closed spaces such as rooms with people and without people and in rooms with medical equipment etc. $[5,6]$. The influence of charged particles on selected organisms was also studied [7-11]. During the measurements carried out in various spaces, particular attention was paid to which levels of ionization, for whatever reason, could be unnatural. This applies to ship cabins for example [12] or, what the topic of this paper constitutes, salt mines. These are the places, where the particles of cosmic rays ionize the atmosphere, can no longer get to. However, in those same places, ionization can be higher, due to the high air purity [13-15].

Studying of air-ions concentration in the salt mines (not only "Wieliczka") is crucial because of the unusual conditions that occur in the underground chambers and tunnels. In theory it can cause the values of this parameter to no longer be within the ranges determined by the appropriate norms (Table I). These norms, established in 1980 in the former USSR (health regulations No. 21) and then accepted in all former Comecon Countries (Standard Comecon No. 790-77; PN-80/Z-08052), currently raise many doubts (this issue is discussed in detail in the paper [16]), though formally still in force. Therefore, this observance is one of the essential conditions in order to, among others, enable the underground healing chambers

\footnotetext{
*e-mail: awisz@gumed.edu.pl
}

to acquire a sanatorium status.

TABLE I

The norms* of small air-ions concentration $(n)$.

\begin{tabular}{l|l|l}
\hline \hline The level of ionization & $n^{-}\left[\right.$ions $\left./ \mathrm{cm}^{3}\right]$ & $n^{+}\left[\right.$ions $\left./ \mathrm{cm}^{3}\right]$ \\
\hline minimal, required & 600 & 400 \\
optimal & $3000-5000$ & $1500-3000$ \\
maximal, admissible & 50000 & 50000
\end{tabular}

*Standart Comecon No. 790-77; (PN-80/Z-08052)

The above norms are established exclusively in reference to the so-called small air-ions - this is consistent with current theories, according to which only this type of ionized air particle influences various organisms, including humans $[2,7,16-19]$. The criterion, according to which air ions are divided into small and heavy (their concentrations are indicated by the letters " $\mathrm{n}$ " and "N", respectively), is connected with a second parameter of ionized particles, known as mobility $(\mu)$. It is defined as the ratio of the additional velocity component (independent of thermal velocity), which air ions gain in the electric field.

Usually the name "small air-ion" is given to ionized particles which have the mobility of $\mu>$ $0.01 \mathrm{~cm}^{2} \mathrm{~V}^{-1} \mathrm{~s}^{-1}$, whilst heavy ones have the mobility of $\mu<0.01 \mathrm{~cm}^{2} \mathrm{~V}^{-1} \mathrm{~s}^{-1}$. Therefore small air-ions are predominant ions in the air: $\mathrm{e}^{-}$(electron), $\mathrm{O}^{-}, \mathrm{O}_{2}^{-}$, $\mathrm{O}^{+}, \mathrm{O}_{2}^{+}, \mathrm{N}^{+}, \mathrm{N}_{2}^{+}\left(\mathrm{N}^{-}\right.$and $\mathrm{N}_{2}^{-}$ions are practically not observed $[17,20])$.

\section{Methods}

Change of air-ions concentration was measured using a Gerdien ion counter (i.e. "integral" air-ion meter - 
Fig. 1). The idea of measurement involves counting of air-ions reaching the electrode disposed centrally within the cylinder, through which the air flows.

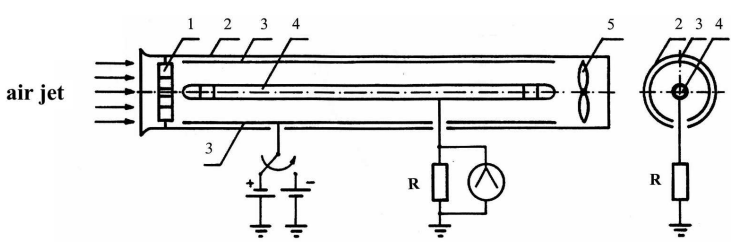

Fig. 1. Cross-section of a meter measuring the global concentration of air-ions (accordingly to [7]); markings: 1 - coaxial cylinders, 2 - test chamber, 3 - voltage electrode, 4 - collective electrode, 5 - vane, $\mathrm{R}-$ height-ohm resistor of the electrometer.

The recorded voltage at resistor $\mathrm{R}$ relates to the number of ions per unit volume of air. The atmospheric air with charged particles flows through slits between a set of coaxial cylinder. The slits reduce the turbulent inflow of air at the input of the instrument. The ion's trajectory is deflected in the electrostatic field towards the axis of the cylinder. The air pumped from the outside entered the instrument chamber at the rate of $6.25 \times 10^{-4} \mathrm{~m}^{3} \mathrm{~s}^{-1}$. The relatively high inlet flow rate, the large diameter of the chamber $(12 \mathrm{~cm})$, and length of the electrode $(32 \mathrm{~cm})$ allowed us to reduce signal fluctuations, to obtain a greater sensitivity and to record charged particles over a relatively wide spectrum of ion mobility.

The used air-ion meter may not register heavy ions of the low mobility - those which can traverse the whole chamber without reaching the collecting electrode 4 . It is further complicated by the fact that particles having the same mobility can still reach the collecting electrode 4, provided they are introduced to the chamber closer to its centre.

Due to the fact that the "integral" air-ion meters can only partially register heavy air-ions is associated with an important parameter of these devices, i.e. critical mobility value $\left(\mu_{1}\right)$. This determines the mobility value above which a given device registers $100 \%$ of air-ions (ionized particles of $\mu<\mu_{1}$ are also registered, but their percentage is difficult to estimate). The critical mobility value depends on the geometrical parameters of the measuring chamber (most importantly: length and cross-section radius) and voltage applied to the electrode 3 (Fig. 1).

This limitation, resulting from the existence of a critical mobility, can be overcome by determining the spectrum of the ion current (the construction and principle of the operation of this type of detectors - "differential" air-ion meters, have been thoroughly discussed in the paper [7]). However, then another difficulty arises. The determination of a single ion current spectrum takes from about dozen minutes to half an hour.

These problems did not influence the measurements conducted in the salt mines. Spectra of the ion currents determined in different places were practically everywhere identical and showed the absence of any impurities. Therefore, determination of this parameter is lim- ited to only a few measurements. In addition, the setting for "integral" air-ion meters of the critical mobility value $\mu_{\mathrm{l}}=0.001 \mathrm{~cm}^{2} \mathrm{~V}^{-1} \mathrm{~s}^{-1}$ ensured the registration of all small air-ions which have an impact on living organisms.

Measuring instruments, used to determine air-ions concentration in the "Wieliczka" Salt Mine, were produced at the Institute of Nuclear Physics in Kraków (INP). They allow the detection of ionized particles starting at level 20 ions $/ \mathrm{cm}^{3}$.

Preliminary research showed that levels of density of ionized particles were relatively high at all the measuring points (several times higher than above ground), as the consequence of the high air purity. To confirm or reject this assumption, an additional single measurement was performed by the "differential" air-ion meter, allowing the allocation of the air-ion spectrum. Because the study conducted in the "Dragon" chamber fully confirmed the fact that the air in the mine is free from any significant contamination, further measurements were taken with the "integral" air-ion meter.

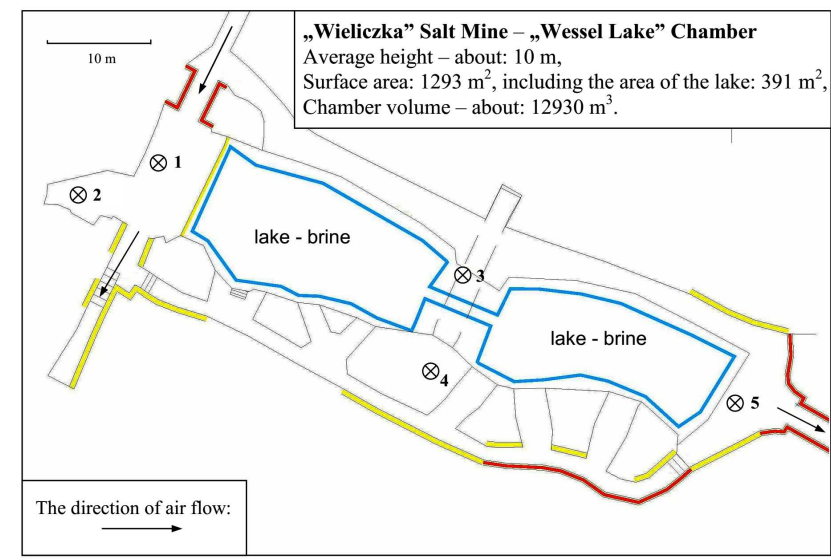

Fig. 2. Measuring points of air-ions concentration in the "Wessel Lake" chamber.

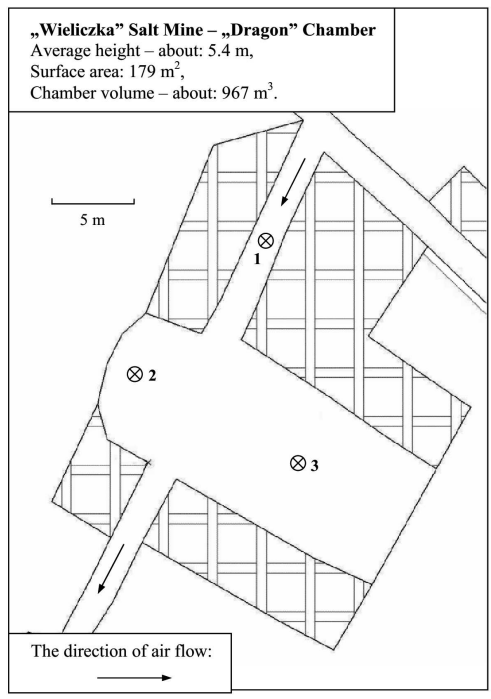

Fig. 3. Measuring points of air-ions concentration in the "Dragon" chamber. 


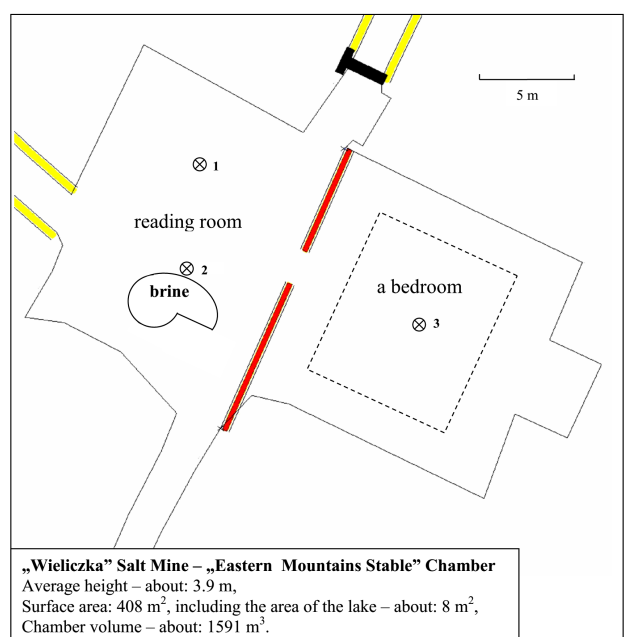

Fig. 4. Measuring points of air-ions concentration in the "Eastern Mountains Stable" chamber.

Measurements were conducted at points shown in Figs. 2, 3 and 4 (about $1 \mathrm{~m}$ above ground) - in each of them at least three times.

The configuration of measuring points was chosen in order to detect any possible differences in air-ions concentration, triggered by some additional factors (e.g. air movement, proximity to salt lakes, additionally equipped chambers etc.).

Only one or two persons from the research team were present in the chambers during the measurements.

\section{Results}

The values of air-ion concentration (negative $-n^{-}$and positive $-n^{+}$) obtained in the all 10 measuring points marked in Figs. 2, 3 and 4, are listed in Table II.

TABLE II

Small air-ions concentration in the chambers of the "Wieliczka" Salt Mine.

\begin{tabular}{c|c|c|c}
\hline \hline Chamber name & $\begin{array}{c}\text { Measuring } \\
\text { point no. }\end{array}$ & $\begin{array}{c}n^{-} \\
{\left[\text {ions } / \mathrm{cm}^{3}\right]}\end{array}$ & $\begin{array}{c}n^{+} \\
{\left[\text {ions } / \mathrm{cm}^{3}\right]}\end{array}$ \\
\hline "Wessel Lake" & 1 & $1750 \pm 230$ & $1540 \pm 110$ \\
& 2 & $610 \pm 80$ & $730 \pm 130$ \\
& 3 & $1240 \pm 280$ & $1800 \pm 340$ \\
& 4 & $1380 \pm 190$ & $1420 \pm 210$ \\
& 5 & $1760 \pm 390$ & $1320 \pm 430$ \\
\hline "Dragon" & 1 & $4150 \pm 450$ & $4200 \pm 440$ \\
& 2 & $4610 \pm 330$ & $4590 \pm 300$ \\
\hline "Eastern Mountains & 1 & $4630 \pm 280$ & $4690 \pm 310$ \\
Stable" & 2 & $2810 \pm 190$ & $2220 \pm 180$ \\
\hline$n^{-}, n^{+}$ & 3 & $2460 \pm 150$ & $1520 \pm 380$ \\
\hline
\end{tabular}

$n^{-}, n^{+}-$air-ions concentration.

The ranges of change of air-ion concentrations $( \pm)$ given in Table II are related to subsequent measurements made at a specific location, as well as thermal fluctuations in the density of the air (mean range \pm 40 ions $/ \mathrm{cm}^{3}$ ).
The two determined spectra for negatively and positively ionized particles (registered in the "Dragon" chamber) demonstrated that for negative air-ions the maximum ion current is for mobility $\mu=2.2 \mathrm{~cm}^{2} \mathrm{~V}^{-1} \mathrm{~s}^{-1}$, and for positive air-ions is for mobility $\mu=1.2 \mathrm{~cm}^{2} \mathrm{~V}^{-1} \mathrm{~s}^{-1}$. This means that air-ions in the chambers of the "Wieliczka" Salt Mine are overwhelmingly (approaching $100 \%$ ) a mixture of particles the $\mathrm{O}_{2}^{-}, \mathrm{O}^{-}, \mathrm{e}^{-}, \mathrm{O}_{2}^{+}$, $\mathrm{O}^{+}, \mathrm{N}_{2}^{+}, \mathrm{N}^{+}$. This shows the very high purity of air in the chambers of this mine. This also confirms some random measurements taken in the 1970s by Niziol in the same mine, in the presently unused "Boczkowski" chamber [20].

It was not possible to precisely determine the level of air-ion concentration in the sleeping quarters of "Eastern Mountains Stable" Chamber (Fig. 4), due to large amount of equipment accumulated in this room as well as materials interfering with measurements (for example electrifying bedding). To a lesser extent, the credibility of the results of the measurements in the "bedroom" of "Eastern Mountains Stable" chamber is influenced by presence of patients for more than half of the time of measurements. As a result of breathing, the atmosphere was saturated with heavy air-ions to an amount that is difficult to estimate [21].

Measurements conducted in the "bedroom" (Fig. 4 point 3) demonstrated a similar level of ionization as in points 1 and 2 of "Eastern Mountains Stable" chamber - it was also in the range of $1500-2500$ ions $/ \mathrm{cm}^{3}$ for air-ions of both charges.

According to the range mentioned above, the absolute error of measurement reached approximately 1000 ions $/ \mathrm{cm}^{3}$, which makes the results worthless. For this reason they have not been included in Table II.

\section{Discussion}

The data in Table I shows that the concentration levels of air-ions in the "Wieliczka" Salt Mine are similar for both electric charges and that, in most cases, they are within the range of $1200-4700$ ions $/ \mathrm{cm}^{3}$. A smaller density of these particles was recorded only in measuring point 2 of "Wessel Lake" chamber as a result of placed there the collection of various pieces of equipment, including electronic equipment (it is the so-called "television corner").

Measurements have shown little effect of the two small lakes situated in the "Wessel Lake" and "Eastern Mountains Stable" chambers on the air-ions concentrations the $n^{-}$and $n^{+}$values, measured on the edge of these containers did not differ excessively from the ones which were registered in other places. The reason for this is the complete salt saturation in these lakes and consequently limited water evaporation. The air humidity in all three of the studied chambers at "Wieliczka" was in the range of $70-75 \%$, at temperatures $c a .13{ }^{\circ} \mathrm{C}$.

The persistence of a greater air-ions concentration in the "Dragon" chamber is due to the fact that it is a completely unused space — surrounded by unused tunnels, 
not visited by people and without any equipment. As a result, the purity of the air is greater.

The doorways separating the individual chambers from the surrounding tunnels were, as far as possible, closed during taking the measurements. It minimized the flow of air, although it did not eliminate it completely (which is why in Figs. 2-4 the direction of this flow has been plotted). However, this flow was barely perceptible and, as demonstrated by more detailed studies, it did not have a significant effect on air-ions concentration. The greatest flow of air, but also below $1 \mathrm{~m} / \mathrm{s}$, appeared in the "Wessel Lake" chamber in measuring point no. 1. From the results presented in Table II it is possible to see that even in this instance the movement of air did not influence in any significant way the density of ionized particles in this place.

The recorded ranges of small air-ions concentration in the "Wieliczka" Salt Mine: 1200-4700 ions $/ \mathrm{cm}^{3}$ exceeds severalfold the values of this parameter in the natural atmosphere above ground. This state persists despite the fact that the depth at which the measurements were taken (135 m below the surface of the earth), is not subjected to the impact of highly energetic components of cosmic rays that ionize the air (responsible for about $19 \%$ of ionized air particles). The reason for the existence of the overstated level of air ionization is due to the aforementioned high purity of air in all studied chambers.

Even though the level of air ionization in the mine is overstated multiple times in the relation to the natural atmosphere, generally it is a positive fact. The comparison of measurement results, summarized in Table II, with the norms in Table I, shows that the levels of air ionization inside the "Wieliczka" Salt Mine not only fall within acceptable range, but also, in most cases, are optimal for humans.

The results of the measurements of air-ions concentration presented and discussed in this paper, relate exclusively to a specific mine. Similar studies were conducted in the 1970s in other Polish salt mines ("Bochnia", "Kłodawa"). They were carried out by scientists from the INP. These studies were only random and carried out using less accurate meters (therefore have not been published), but with a tolerance of $25 \%$, they gave results similar to those obtained in "Wieliczka" ("Bochnia": $n^{-}=1260-5790$ ions $/ \mathrm{cm}^{3}, n^{+}=920-5860$ ions $/ \mathrm{cm}^{3}$; "Kłodawa": $\quad n^{-}=460-4120$ ions $/ \mathrm{cm}^{3}, n^{+}=$ $550-5380$ ions $\left./ \mathrm{cm}^{3}\right)$. The levels of air ionization given in this paper can therefore be considered in more general terms. Most probably in the chambers and drifts of other salt mines, which are also located at depths of over a hundred meters below the surface of the earth, the values of air-ion concentration are similar to those presented here in Table II.

Taking into account all the issues considered in the study reported here, concerning the issues of air ionization in the healing chambers of "Wieliczka" Salt Mine, it is possible to assume that the following conclusions result from them:
- Despite the lack of one of the factors responsible for ionization, namely these particles of cosmic rays, which ionize the air, small air-ions concentration in the healing chambers and drifts of the "Wieliczka" Salt Mine, are several times greater than the concentration of these particles occurring naturally in the atmosphere above the ground. The reason for this is the low level of dust particles occurring in the air of the mine, making it practically impossible for the small air-ions to be transformed into heavy ions.

- The small lakes, found in some of the healing chambers of the "Wieliczka" Salt Mine, have no influence on the level of air ionization surrounding them. It is the effect of low air temperature, low speed of air stream and elevated air humidity, typical for salt mine chambers.

- The natural movement of the air in the chambers and drifts of the "Wieliczka" Salt Mine has no significant effect on the level of air ionization.

- Levels of air ionization in the healing chambers of the "Wieliczka" Salt Mine: "Wessel Lake", "Dragon" and "Eastern Mountains Stable", are close to those which according to the current norms have been defined as optimal for humans.

- Comparison of air-ions concentration values set in the salt mine "Wieliczka" and in the chambers and drifts of the other of salt mines, which are also located at depths of over a hundred meters below the surface of the earth, showed similar levels of air ionization, with a tolerance of $25 \%$.

- Random measurements conducted in two other salt mines in Poland ("Bochnia", "Kłodawa") showed very similar results to those obtained in "Wieliczka". Therefore it can be assumed that the levels of ionization, presented in this paper, can be extrapolated to other salt mines, located at a depth of about $135 \mathrm{~m}$.

\section{References}

[1] A. Hirsikko, T. Nieminen, S. Gagné, K. Lehtipalo, H.E. Manninen, M. Ehn, U. Hőrrak, V.-M. Kerminen, L. Laakso, P.H. McMurry, A. Mirme, S. Mirme, T. Petäjä, H. Tammet, V. Vakkari, M. Vana, M. Kulmala, Atmos. Chem. Phys. 11, 767 (2011).

[2] A. Wiszniewski, Med. Pr. 48, 427 (1997).

[3] A. Wiszniewski, Ann. Acad. Med. Gedan. 34, 341 (2004).

[4] Z. Klusek, A. Wiszniewski, J. Jakacki, Oceanologia 46, 459 (2004).

[5] A. Wiszniewski, Hig. Pr. 3, 37 (1997).

[6] A. Wiszniewski, M. Baran, Med. Pr. 52, 271 (2001).

[7] A. Wiszniewski, D. Janczewski, Med. Pr. 3, 289 (1993). 
[8] A. Wiszniewski, T. Kretowicz, J. Appl. Genet. 40, 129 (1999).

[9] A. Wiszniewski, M. Szczygieł, S. Hudy, Acta Microbiol. Pol. 52, 201 (2003).

[10] A. Wiszniewski, A. Suchanowski, Pol. J. Environ. Stud. 17, 801 (2008).

[11] A. Wiszniewski, A. Suchanowski, B. Wielgomas, Pol. J. Environ. Stud. 23, 521 (2013).

[12] A. Wiszniewski, Med. Pr. 61, 299 (2010).

[13] M.R. Călin, C.A. Simion, G.I. Simionca, M.A. Călin, A.E. Druker, Rom. Rep. Phys. 63, 483 (2011).

[14] Y.M. Gavrilyuk, A.M. Gangapshev, V.V. Kuzminov, S.I. Panasenko, S.S. Ratkevich, Bull. Russ. Acad. Sci. Phys. 75, 547 (2011).

[15] A. Stochioiu, S. Bercea, M. Sahagia, C. Ivan, I. Tudor, A. Celarel, Rom. J. Phys. 56, 757 (2011).
[16] A. Wiszniewski, Med. Pr. 61, 241 (2010).

[17] R.I. Kavet, J.M. Charry, Air-Ions - Physical and Biological Aspects, CRC Press, Boca Raton, Florida 1987.

[18] H. Korniewicz, Z. Grabarczyk, K. Gryz, J. Karpowicz, Protection of Human in Work Environment (CPBR No. 11.1), CIOP, Warszawa 1991.

[19] Z.J. Grabarczyk, Air Ionization in Environment of Life and of Work, CIOP, Warszawa 2000.

[20] Z. Jura, B. Niziol, Z. Zakrocki, Report No. 841 D of Institute of the Nuclear Physics, Kraków 1973.

[21] A. Suchanowski, A. Wiszniewski, Pol. J. Environ. Stud. 8, 259 (1999). 